\title{
Differences in weight gain in hypertensive and diabetic elderly patients
} Primary care study

\author{
Zoltán Jancsó, ${ }^{1}$ Eszter Halmy, ${ }^{2,3}$ Imre Rurik $^{1,4}$ \\ ${ }^{1}$ Department of Family and Occupational Medicine, Faculty of Public Health, \\ University of Debrecen, 4032 Debrecen, Nagyerdei krt. 98. \\ ${ }^{2}$ Hungarian Society for the Study of Obesity 1035 Budapest, Vörösvári út 15 \\ ${ }^{3}$ Platon Health Services and Advisory Ltd. 1025 Budapest, Boróka u. 9. \\ ${ }^{4}$ Primary Care Centre, Budapest XX. 1201 Budapest, Vörösmarty u. 5, \\ Hungary
}

\section{Corresponding author:}

Imre Rurik, MD, PhD, MSc

Head, Department of Family and Occupational Medicine,

Faculty of Public Health, University of Debrecen

Phone: +36 52255252 Fax: + 3652255253

E: $\underline{\text { rurik@med.unideb.hu and Rurik.Dr@t-online.hu }}$ 


\begin{abstract}

\section{Background}

Treatment and care of elderly patients with diabetes and hypertension means a hard task in primary care. Patients with these two components of metabolic syndrome are often overweight or obese. Although some parameters of metabolic syndrome are usually measured in a medical setting, checking body weight is usually done by the patients.
\end{abstract}

\title{
Aim
}

The aim of this study is to analyse the patients' self-recorded data on weight and compare them according to hypertension and diabetes.

\section{Patients and Methods}

Five hundred and forty people (225 men and 315 women) between 60 and 75 years of age were eventually selected in primary care settings.

Retrospective self-recorded data on recent weights and every decade since the age of 20, as well as the decade prior to diagnosis were collected. The data of patients with and without diabetes and/or hypertension were compared.

\section{Results}

The current mean body weight was significantly higher in all groups than at the age of 20. Compared with the control group, hypertensive men and women were approximately of the same weight in their twenties and, also, recently, but they gained more weight in the $4^{\text {th }}$ and $5^{\text {th }}$ decades of their life.

Diabetics started at higher weights. The greatest weight gain was observed as follows: between 20-30 years and 30-40 years in men and women, respectively, as well as between 50-60 years of age and in the last decade prior to diagnosis in both genders. Weight gain in the control group was steady at a lower rate.

\section{Conclusions}

Weight gain between 20-40 years of age could be an important factor in the aetiology of diabetes. Stable or at least limited weight gain may be a preventive factor.

Considering the limitations of the study, further and decades long epidemiological evaluations are suggested in a larger study population.

Keywords: diabetes, elderly, Hungarian, hypertension, metabolic syndrome, obesity, primary care, weight gain 


\section{BACKGROUND}

Since the concept of metabolic syndrome (MS) was introduced into medical knowledge, its definition and components have often changed. The actual and summarized definition of MS has been widely accepted now [1].

Diabetes and hypertension have a pivotal role within MS components. Both are diagnostic entities and are often related to significant weight gain $[2,3,4,5]$. There are treatment options to optimize glycaemic control also affecting weight gain [6]. There is no doubt, that becoming overweight or obese takes many years perhaps decades, although obesity is often present in childhood and adolescence [7,8,9,10,11]. Genetic factors, lifestyle and social elements, diversity of cultural and economic background could be important as well, but mainly nutritional habits alone or combined with sedentary lifestyle are the real reasons for growing fat $[4,12,13]$. Weight change during old age often remains unexplored $[12,14,15]$. Weight gain is considered as part of the normal ageing process. The controversial association between weight change and mortality has been frequently evaluated $[16,17]$. The associations with morbidity are clearer, showing that the prevalence of hypertension, diabetes, dyslipidaemia, and metabolic syndrome substantially increases with growing body mass index (BMI). These findings have an important public health implication for the prevention and treatment of obesity [18].

Our previous pilot-study found differences between the dynamicity of weight gain of obese, diabetic and hypertensive patient [8]. Other studies reported that higher body weight increased the risk of hypertension in a dosedependent manner, and there was no advantage of having been previously lean [19]. Weight gain was associated with an increased risk of pre-diabetic condition, greater in those who were not overweight in childhood [20]. Many other studies provide data on components of MS among elderly and middle-aged persons in different populations $[1,2,21,22,23,24]$. Some of our previous research focussed on the life style and nutrition of elderly people [25,26,27].

Elderly people represent the majority of patients in almost all medical settings; therefore they have become important target population for biomedical research. Usually, the components of MS develop gradually with senescence and they often go under-detected [22].

A medical setting is required to measure parameters of MS (plasma glucose level, lipids, even blood pressure etc.), while body weight and height are usually checked by the individuals themselves. Although many people regularly measure their own body weight, remember these data, they rarely store or compare these records. 


\section{AIM}

The objective of this study was to evaluate the life long weight changes of different patients groups. The research questions of our evaluation were as follows:

- Are there differences between the decade-long dynamics of weight changes in hypertensive or diabetic patients and people free from these conditions?

- Are there gender-based differences?

It was a goal as well to confirm our previous findings; therefore a larger primary care population was involved. The method was modified to improve the validity of patients' recorded data.

\section{METHOD}

\section{Setting}

Primary care centre in Budapest and the participating practice in and around Debrecen. There were subjects from the capital, a large city and rural areas as well.

\section{Selection of patients}

People (between 60 and 75 years of age) who visited for any reasons the primary care surgeries (having actual complaints, coming for regular screening, drug prescription, etc.) were consecutively selected.

Exclusion criteria were: serious impairment of visual, acoustic or mental capacity and participation in our pilot study [8]. There were 2 people who refused answering. Another exclusion criterion was introduced to check the validity of self reported data. The upper cut-off point was 75 years of age, because the supposed unreliability of data and deterioration of memory in the senescence.

This evaluation was simpler than the previous one. The participants were asked to fill in a questionnaire and subscribe an informed consent form. The permission of the local Ethical Committee (South Budapest region, Jáhn Ferenc Hospital, 20000821) was obtained in advance.

\section{Questionnaire}

The form contained questions regarding self-recorded data of body weight in each life decade (at 20, 30, 40, 50, 60 years, currently and the highest), body heights at 20 years and recently. Changes in body weight over the last decade prior to the diagnosis of diabetes and/or hypertension was also included (see Appendix).

After completing the questionnaire, the participants' actual body weight was measured and 112 subjects were excluded since the difference between the self-reported and the measured data exceeded $3 \mathrm{~kg}$.

Data analysis 
The participants were divided into four groups to compare diabetic (DM), hypertensive (HYP) men and women, patients with both illnesses (HyDm) and people having neither diabetes nor hypertension (None), as a control group.

Means and \pm SD of weight data were counted, and the actual BMI was calculated. Data on body weight, diagnoses itself and no other confounding variables were considered, and evaluated using the chi-square test. A probability level of $\mathrm{p}<0.05$ was considered as significant. The analysis was performed using the statistical package Stata 8.2 software (Statacorp LP. College Station, TX, USA).

Only data relevant to the topic are presented in this paper. Medication, therapeutic results, failure and success in achieving target levels were evaluated for daily medical purposes, but not in this study.

\section{RESULTS}

Data of 540 people (225 men and 315 women) were evaluated, after the exclusion of unreliable data. The actual means \pm SD of body weights were 79.1 $\pm 13.2 \mathrm{~kg}$ in men and $70.2 \pm 14.8 \mathrm{~kg}$ in women. There were $22 \mathrm{men}$ and 28 women diagnosed as both hypertensive and diabetic. The mean age of diagnosing hypertension was $55.2 \pm 8.0$ years in men and $55.3 \pm 9.1$ in women, while diabetes was diagnosed at the age of $58.2 \pm 8.7$ years and $54.2 \pm 9.5$ years in males and females, respectively. In some cases, there was a wide range, 9-21 years, between the two diagnoses. There were only 8 patients $(6$ women and 2 men) who had developed diabetes first and hypertension later. Table 1. presents the distribution and high prevalence of obese and overweight persons within study population. Table $\mathbf{2}$. and $\mathbf{3}$. present the dynamics of weight gain of men and women, comparing the diagnostic categories. The increase of body weight was significant in all columns by decades, in both genders. The highest body weight was reached by $72 \%$ of patients in their seventh and by $26 \%$ in the sixth life decades. Comparing the current weight data to those at 20 years of age, a statistically significant difference was noted $(\mathrm{p}<0.001)$. Table 2. demonstrates that hypertensive men had similar body weight to those in the control group. Diabetic men (with or without hypertension) started at a higher body weight from their twenties and they gained more than $17 \mathrm{~kg}$, so they had the highest current weight, dominantly after 60 years of age. They gained significantly more weight between 20-30 years, and thereafter in the sixth decade. Males with hypertension had lower weight as a young man and gained less weight than diabetics did. Diabetics gained significantly more weight in the last decade prior to diagnosis. The life-long weight gain in the control group was steady but lower.

Identical data for women are presented in Table 3. Hypertensive women had the lowest body weight in their twenties, $5 \mathrm{~kg}$ less than diabetics had. They gained 2-4 $\mathrm{kg}$ by decades, and reached similar weight than the control ("healthy") group. Differences between decades were statistically not significant 
except those marked with *. Diabetic women (with or without hypertension) had higher youth body weights and recorded the highest increase between 30-40 years. This gain was significantly higher than in the non-diabetic group $(\mathrm{p}=$ 0.036). Within the diabetic groups, weight increase during the 10 years before diagnosis was about twofold compared to other groups of the same age ( $\mathrm{p}=$ 0.04). Among non-diabetic women the increase in body weight was steadier.

\section{DISCUSSION}

The phenomenon of weight gain from the youth to the elderly was observed, as reported in many other studies as well. Nevertheless there were visible differences between weight changes of different groups of patients as presented in the tables. In both groups, the recorded maximum weights were higher than the current ones, which was perhaps due to the normal ageing process [28].

We compared only changes in body weight. Changes (decrease) in body height over decades used to be less, resulting smaller changes in the BMI, than higher changes in body weight can do. The same BMI does not mean the same body weight and height in different life periods. Due to the normal decrease in body height, the same weight in the elderly means a higher BMI. The same body weight means less muscle and more adipose tissue, which is known as sarcopenia, a silent phenomenon in the elderly [29]. People usually underestimate their weight and over-estimate their body height [30]. It was more common among subjects with higher BMI; they under-estimated their weight compared with those with smaller BMI [31]. Diabetic and hypertensive people are more likely to under-report their weight [32]. In a similar fashion, a lower BMI cut-off of $29.2 \mathrm{~kg} / \mathrm{m}^{2}$ was identified for both genders for the definition of obesity based on self-report [33]. Due to this bias, our study focused simply on weight, instead of calculating recent and former BMIs. Supposedly, underestimated data were recorded earlier as well, in all decades; however, this may not deform visible trends.

Elements of MS, such as lipid disorders, elevated BMI and waist circumference, risk of hypertension, and diabetes correlated with increased body weight [22]. It is of importance which life period is characterized by weight gain. Prime age (age 25-10 years ago) and middle life weight gain (last 10 years) were compared in a representative USA population. All weight gain groups had increased odds of low HDL and high triglycerides relative to participants with continuously stable weights. No significant associations were found between weight history and hypertension or high glucose [34]. Greater weight gain at any age related to elevated adult blood pressure, but faster weight gains in infancy and young childhood did not pose a higher risk than did gains at other ages [35]. Weight gain after 20 years of age substantially increased the risk of prehypertension in non-hypertensive individuals, while weight loss significantly lowered it, emphasizing the importance of weight control throughout adulthood in preventing hypertension [36]. To lose or not gain weight was an independent 
prognostic factor to achieve the blood pressure goal in all the patients [37]. It is important not only in prevention, but in treatment as well. Our data did not confirm this strong correlation between blood pressure and weight gain in adulthood.

It is still debated, whether there are critical early periods for obesity or not, if excessive weight gains during infancy, childhood or even very early neonatal life has a greater impact on long-term fat deposition, or not [38]. Young adults who maintained stable BMI over time exhibited minimum progression of risk factors and lower incidence of metabolic syndrome, regardless of baseline BMI. Greater effort in public health should be aimed at long-term weight stabilization [39]. Weight history may contribute to our understanding of why some obese old people are metabolically healthy, but others are not [34].

Patients with metabolic syndrome have a 1.5- to 3-fold increase in their risk to develop coronary heart disease and stroke. However, no official guidelines concerning the pharmacological management of individuals with metabolic syndrome are at the general practitioners' disposal at present [40].

\section{Main findings}

In order to answer the research question properly, a critical comparison between data is needed. Life-long weight gains were more characteristic in both groups and genders, mainly in the fourth and fifth decades. Among diabetics, weight gains in the decade prior to the diagnosis and, also, in the $3^{\text {rd }}$ decade in males and 4th decade in females appeared to be a clear trend. Hypertensive patients had similar, but not so characteristic data.

The similarities between the control and hypertensive groups may be due to the high prevalence of hypertension among the elderly. It seems, that steady weight or a slow increase in body weight may play a preventive role in developing diabetes. This theory is supported by the following observations: -diabetic women and men had higher body weights in their youth, and they gained significantly more weight in their third and fourth decades; - weight gain by diabetics in the decades prior to the diagnoses was significantly higher in both genders; -rapid weight gain before 40 years of age was observed by most of the diabetics; -people without diabetes had a more balanced increase in body weight.

\section{Study limitations}

There is no researcher who could be able conducting decade's long study, following patients for a life long period, registering correctly their anthropometric parameters. It is the reason, why another studies with exactly measured anthropometric data covered never decades only years and presented different outcomes [22,34-39]. Accuracy of data and longevity in follow up need 
some compromise. Nevertheless we are aware of the theoretical and practical limitations of our study:

- the reliability of data based on memory and personal records could be the weakest point,

- there were overlaps between the different groups, and data of patients with both illnesses were often divergent from those with only one disease,

-weight gain during pregnancies was very common. Different gestational weight gain recommendations in overweight and obese women were often neglected by patients [41], and might not be reflected in their weight data,

- therapy and interventions started at younger age may have modified the findings $[6,42]$,

- this age cohort (born between 1925-1950) grew up among highly different socio-economic circumstances and conditions and these factors were not investigated,

- genetic elements and other relations remained undiscovered,

- the study population could not be considered as representative, although urban and rural inhabitants were involved as well. Frequent visitors to primary care surgeries were over-represented; they surely did not belong to the "healthy elderly" population.

\section{CONCLUSION}

Stability in body weight or only limited and slow continuous weight gain could be considered as preventive factor against some components of MS, mainly diabetes.

More reliable data should be collected from different sources and cohort followup epidemiological evaluations are needed in a larger population, in the frame of international cooperation, comparing ethnically diverse populations, as it was recommended earlier in our pilot study [8].

$\underline{\text { Public health implication }}$

Primary care physicians should not be just inactive observers; they must be more active in the prevention of life-long weight gain in the future. We propose critical thinking and decision-making, using the clinicians' expertise, with due consideration to the patients' individual circumstances [43]. There is no other medical setting where patient-doctor collaboration is as close as in primary care. Patients need more benefit from this proximity.

Acknowledgement: We are very grateful to participating family physicinans. Thanks to practice nurse, Mrs. Vally Kisow, for collecting data, and to Mrs. Justina N.Jánossy for English correction.

\section{Conflict of interest: none. Financial support, accepted grant: none}




\section{Author's contributions:}

ZJ organized the data collection, established and kept correspondence with largest part of participating practices, searched literature, performed text writing. EH searched literature and she has been involved in text writing.

IR designed the study, made literature search, corresponded with some of the practices and performed final text editing.

\section{REFERENCES}

[1] Alberti KG, Zimmet P, Shaw J. IDF Epidemiology Task Force Consensus Group. The metabolic syndrome- a new worldwide definition. Lancet 2005;366:1059-62.

[2] Yang G, Xiang YB, Zheng W, Xu WH, Zhang X, Li HL, Shu XO. Body weight and weight change in relation to blood pressure in normotensive men. $\mathrm{J}$ Hum Hypertens 2007;21:45-52

[3] Jacob AN, Salinas K, Adams-Huet B, Raskin P. Potential cause of weight gain in type 1 diabetes mellitus. Diabetes Obes Metab 2006;8:404-11.

[4] Shai I, Jiang R, Manson JE, Stampfer MJ, Willett WC, Colditz GA, Hu FB. Ethnicity, obesity an risk of type 2 diabetes in women: a 20-year follow-up study. Diabetes Care 2006;29:1589-90.

[5] Turley M, Tobias M, Paul S. Non-fatal disease burden associated with excess body mass index and waist circumference in New Zealand adults. Aust $\mathrm{N}$ Z Public Health 2006;30:231-7.

[6] Joffe D, Yanagisawa RT. Metabolic syndrome and type 2 diabetes: can we stop the weight gain with diabetes? Med Clin North Am. 2007;91:1107-23. [7] Thompson JN. Fetal nutrition and adult hypertension, diabetes, obesity, and coronary artery disease. Neonatal Netw 2007;26:235-40.

[8] Rurik I, Sandholzer H, Kalabay L. Does the dinamicity of weight gain predict the elements of metabolic syndrome? Med Sci Monit 2009;15: CR40-44 [9] Molnar D, Erhardt É. Severe childhood obesity: What are the keys for management? Int J Pediatr Obesity 2008; 3(S2): 9-14.

[10] Ilyés I. Childhood obesity is a cardiovascular risk factor. Eur J Gen Pract 1996;1:173.

[11] Ilyés I, Blatniczky L. Obesitas, metabolic syndrome. in: Péter F(ed)

Childhood endocrinology. Semmelweis. Budapest, 2010. pp. 371-384.

[12] Gallus S, Colombo P, Scarpino V, Zuccaro P, Negri E, Apolone G, Vecchia CL. Overweight and obesity in Italian adults 2004, and an overview of trends since 1983. Eur J Clin Nutr 2006;60:1174-9.

[13] Rurik I, Antal M. Nutritional habits and life style practice of elderly people in Hungary. Acta Alim 2003;32:77-88. 
[14] Hays NP, Bathalon GP, Roubenoff R, McCrory MA, Roberts SB. Eating behaviour and weight change in healthy postmenopausal women: results of a 4year longitudinal study. J Gerontol A Biol Sci Med Sci. 2006;61:608-15. [15] Liese AD, Döring A, Hense AW et al. Five years changes in waist circumference, body mass index and obesity in Augsburg, Germany. Eur J Nutr 2001;17:912-6.

[16] Corrada MM, Kawas CH, Mozaffar F, Paganini-Hill A. Association of body mass index and weight change with all-cause mortality in the elderly. Am $\mathbf{J}$ Epidemiol 2006;163:939-49.

[17] Seidell JC, Vissscher TLS. Body weight and weight change and their health implications for the elderly. Eur J Clin Nutr 2000; 54: S3 33-9.

[18] Nguyen NT, Magno CP, Lane KT, Hinojosa MW, Lane JS. Association of hypertension, diabetes, dyslipidemia, and metabolic syndrome with obesity: findings from the National Health and Nutrition Examination Survey, 1999 to 2004. J Am Coll Surg. 2008;207:928-34.

[19] Williams PT. Increases in weight and body size increase the odds for hypertension during 7 years of follow-up. Obesity (Silver Spring) 2008;16:25418.

[20] Black E, Holst C, Astrup A, Toubro S, Echwald S, Pedersen O, Sørensen TI. Long-term influences of body-weight changes, independent of the attained weight, on risk of impaired glucose tolerance and Type 2 diabetes. Diabet Med Med. 2005;22:1199-205.

[21] James WP. The epidemiology of obesity: the size of the problem. J Intern Med 2008;263:336-52.

[22] Williams PT, Hoffman K, La I. Weight-related increases in hypertension, hypercholesterolemia, and diabetes risk in normal weight male and female runners. Arterioscler Thromb Vasc Biol. 2007;27:1811-9.

[23] Katona É, Settakis G, Varga Z, Paragh G, Bereczki D, Fülesdi B, Páll D. Target-organ damage in adolescent hypertension. Journal of Neurological Sciences 2006; 247:138-143.

[24] Vajó Z, Ács N, Tóth K, Dinya E, Paragh G, Császár A. Cardiovascular risk status and primary prevention in postmenopausal women: the MENOCARD study. Wien Klin Wochenschr 2009;121:202-208.

[25] Rurik I, Sandholzer H. Obesity among Hungarian elderly. Act Aliment 2009;38:361-367

[26] Rurik I. Evaluation on lifestyle and nutrition among Hungarian elderly. Zeitsch Gerontol Geriat 2004;37:33-36.

[27] Rurik I. Diet and weight gain of elderly diabetic patients. Eur J Gen Pract 2006; 12:85-87.

[28] Heymsfield SB, Nuňez C, Testolin C, Gallagher D. Anthropometry and methods of body composition measurement for research and field application in the elderly. Eur J Clin Nutr 2000;54:S3 26-32. 
[29] Waters DL, Baumgartner RN, Garry PJ. Sarcopenia: current perspectives. J Nutr Health Aging 2000;4:133-139.

[30] Taylor AW, Dal Grande E, Gill TK, Chittleborough CR, Wilson DH, Adams RJ, Grant JF, Phillips P, Appleton S, Ruffin RE. How valid are self reported height and weight? A comparison between CATI self report and clinic measurements using a large cohort study. Aust N Z J Public Health 2006;30:238-46.

[31] Wada K, Tamakoshi K, Tsunekawa T, Otsuka R, Zhang H, Murata C, Nagasawa N, Matsushita K, Sugiura K, Yatsuya H, Toyoshima H.

Validity of self-reported height and weight in a Japanese workplace population. Int J Obes (Lond) 2005;29:1093-9.

[32] Yannakoulia M, Panagiotakos DB, Pitsavos C, Stefanadis C. Correlates of BMI misreporting among apparently healthy individuals: the ATTICA study. Obesity (Silver Spring) 2006;14:894-901.

[33] Dauphinot V, Wolff H, Naudin F, Guéguen R, Sermet C, Gaspoz JM, Kossovsky MP. New obesity body mass index threshold for self-reported data. J Epidemiol Community Health 2009;63:128-32.

[34] Alley DE, Chang VW. Metabolic syndrome and weight gain in adulthood. J Gerontol A Biol Sci Med 2010;65:111-7.

[35] Adair LS, Martorell R, Stein AD, Hallal PC, Sachdev HS, Prabhakaran D, Wills AK, Norris SA, Dahly DL, Lee NR, Victora CG. Size at birth, weight gain in infancy and childhood, and adult blood pressure in 5 low- and middleincome-country cohorts: when does weight gain matter? Am J Clin Nutr 2009;89:1383-92.

[36] Yang G, Shu XO, Gao YT, Zhang X, Li H, Zheng W. Impacts of weight change on prehypertension in middle-aged and elderly women. Int J Obes (Lond) 2007;31:1818-25.

[37] Pascual JM, Rodilla E, Costa JA, Perez-Lahiguera F, Gonzalez C, Lurbe E, Redón J. Body weight variation and control of cardiovascular risk factors in essential hypertension. Blood Press 2009;18:247-54.

[38] Ong KK. Size at birth, postnatal growth and risk of obesity. Horm Res 2006;65 S3:65-9.

[39] Lloyd-Jones DM, Liu K, Colangelo LA, Yan LL, Klein L, Loria CM, Lewis CE, Savage P. Consistently stable or decreased body mass index in young adulthood and longitudinal changes in metabolic syndrome components: the Coronary Artery Risk Development in Young Adults Study. Circulation 2007;115:1004-11.

[40] De Flines J, Scheen AJ. Management of metabolic syndrome and associated cardiovascular risk factors. Acta Gastroenterol Belg 2010;73:261-6. [41] Beyerlein A, Lack N, von Kries R. Within-population average ranges compared with Institute of Medicine recommendations for gestational weight gain. Obstet Gynaecol 2010;116:1111-8. 
[42] Bastianens H, Sunaert P, Wens J, Sabbe B, Jenkins L, Nobels F, Snauwaert B, van Royen P. Suppporting diabetes self-management programme focusing on diet and exercice. Prim Care Diabetes 2009; 3:103-9.

[43] Jenicek M, Croskerry P, Hitchcock DL. Evidence and its uses in health care and research: The role of critical thinking. Med Sci Monit 2010;17:RA12-17.

\section{TABLES}

Table 1. Distribution of men and women according to recent body mass index (BMI)

\begin{tabular}{|c|c|c|c|c|c|}
\hline \multicolumn{5}{|c|}{ BMI groups $\left[\mathrm{kg} / \mathrm{m}^{2}\right]$} \\
\hline $\begin{array}{c}\text { Normal } \\
(\mathbf{1 8 . 5 - 2 4 . 9 )}\end{array}$ & \multicolumn{2}{|c|}{$\begin{array}{c}\text { Overweigt } \\
(\mathbf{2 5 - 2 9 . 9 )}\end{array}$} & \multicolumn{2}{|c|}{$\begin{array}{c}\text { Obese } \\
(\mathbf{3 0}<)\end{array}$} \\
\hline Men & Women & Men & Women & Men & Women \\
\hline $\mathbf{7 9}$ & 91 & $\mathbf{8 6}$ & 156 & $\mathbf{6 0}$ & 68 \\
\hline
\end{tabular}


Table 2. Means of self-recorded current and maximum weight $[\mathrm{kg}]$ and weight gain between decades $[\Delta]$, and last decade prior to diagnosis of men, with hypertension (HYP), with diabetes (DM), with both (HyDm) and with neither disease (control group-None )

\begin{tabular}{|l|c|c|c|c|c|c|c|c|}
\hline MEN & None & & HYP & & DM & & HyDm & \\
\hline \multicolumn{1}{|c|}{$\mathbf{n : ~ 2 2 5}$} & $\mathbf{6 1}$ & & $\mathbf{1 0 4}$ & & $\mathbf{3 8}$ & & $\mathbf{2 2}$ & \\
\hline Age decades & & $\Delta$ & & $\Delta$ & & $\Delta$ & & $\Delta$ \\
\hline 20 years & $\mathbf{6 7 . 6}$ & & $\mathbf{6 6 . 8}$ & & $\mathbf{7 3 . 0}$ & & $\mathbf{6 9 . 7}$ & \\
\hline 30 years & $\mathbf{6 8 . 9}$ & 1.3 & $\mathbf{6 9 . 8}$ & 1.0 & $\mathbf{7 9 . 1}$ & $* 6.1$ & $\mathbf{7 1 . 2}$ & 1.5 \\
\hline 40 years & $\mathbf{7 0 . 2}$ & 1.3 & $\mathbf{7 3 . 1}$ & 3.3 & $\mathbf{8 2 . 1}$ & 3.0 & $\mathbf{7 2 . 1}$ & 1.1 \\
\hline 50 years & $\mathbf{7 2 . 9}$ & 2.7 & $\mathbf{7 6 . 2}$ & 3.1 & $\mathbf{8 4 . 2}$ & 2.1 & $\mathbf{7 5 . 2}$ & 3.1 \\
\hline 60 years & $\mathbf{7 5 . 1}$ & 2.2 & $\mathbf{7 6 . 6}$ & 0.4 & $\mathbf{8 9 . 5}$ & $* 5.3$ & $\mathbf{7 9 . 8}$ & $* 4.6$ \\
\hline Current & $\mathbf{7 5 . 7}$ & 0.6 & $\mathbf{7 7 . 4}$ & 0.8 & $\mathbf{9 0 . 2}$ & 1.3 & $\mathbf{8 4 . 1}$ & 5.3 \\
\hline Last prior to diagnosis & & & & 1.8 & & 3.2 & & 3.3 \\
\hline maximum & $\mathbf{8 2 . 6}$ & & $\mathbf{8 2 . 1}$ & & $\mathbf{9 1 . 1}$ & & $\mathbf{9 0 . 9}$ & \\
\hline
\end{tabular}

* Significant $(\mathrm{p}<0.05)$ difference between decades of different diagnostic groups.

Table 3. Means of self-recorded current and maximum weight $[\mathrm{kg}]$ and weight gain between decades $[\Delta]$, and last decade prior to diagnosis of women, with hypertension $(\mathbf{H Y P})$, (with diabetes (DM), with both (HyDm), and with neither disease (control group- None )

\begin{tabular}{|l|c|r|r|r|r|r|r|r|}
\hline WOMEN & None & & HYP & & DM & & HyDm & \\
\hline \multicolumn{1}{|c|}{$\mathbf{n :} \mathbf{3 1 5}$} & $\mathbf{6 5}$ & & $\mathbf{1 8 0}$ & & $\mathbf{4 2}$ & & $\mathbf{2 8}$ & \\
\hline Age decades & & 4 & & 4 & & $\Delta$ & & 4 \\
\hline 20 years & $\mathbf{5 4 . 8}$ & & $\mathbf{5 4 . 1}$ & & $\mathbf{5 9 . 1}$ & & $\mathbf{6 0 . 2}$ & \\
\hline 30 years & $\mathbf{5 8 . 1}$ & 3.3 & $\mathbf{5 6 . 2}$ & 2.1 & $\mathbf{6 0 . 2}$ & 1.1 & $\mathbf{6 3 . 2}$ & 3.0 \\
\hline 40 years & $\mathbf{6 1 . 0}$ & 2.9 & $\mathbf{5 9 . 8}$ & 3.6 & $\mathbf{7 1 . 1}$ & $* 10.9$ & $\mathbf{6 7 . 9}$ & $* 4.7$ \\
\hline 50 years & $\mathbf{6 5 . 9}$ & 4.9 & $\mathbf{6 4 . 0}$ & 4.2 & $\mathbf{7 3 . 6}$ & 2.5 & $\mathbf{6 9 . 0}$ & 1.1 \\
\hline 60 years & $\mathbf{6 6 . 5}$ & 0.6 & $\mathbf{6 7 . 9}$ & $* 3.9$ & $\mathbf{7 7 . 0}$ & $* 3.4$ & $\mathbf{6 9 . 2}$ & 0.2 \\
\hline Current & $\mathbf{6 7 . 9}$ & 1.4 & $\mathbf{6 8 . 6}$ & 0.7 & $\mathbf{7 8 . 5}$ & 1.5 & $\mathbf{7 3 . 9}$ & 4.7 \\
\hline Last prior to diagnosis & & & & 3.9 & & 6.3 & & 6.4 \\
\hline Maximum & $\mathbf{6 9 . 7}$ & & $\mathbf{7 3 . 3}$ & & $\mathbf{8 1 . 9}$ & & $\mathbf{8 2 . 6}$ & \\
\hline
\end{tabular}

* Significant $(\mathrm{p}<0.05)$ difference between decades of different diagnostic groups.

\section{Appendix}

English translation of the Hungarian questionnaire 


\section{Questionnaire for patients}

Weight gain

\section{Dear patients,}

For scientific research I ask you to give data about your body weight in your different life period, as you remember.

If you have some your own record about this, very close to decade (plus, minus 1-2 y) (medical papers, hospital reports) please use these data.

Please try to be as correct as possible.

If you do not remember data of one of decades, please skip this.

\begin{tabular}{|c|l|l|l|}
\hline Recent body weight & Rg & Recent body high & $\mathrm{cm}$ \\
\hline Body weight at 20y & & $\begin{array}{l}\text { Body high at } 20 \\
\text { year }\end{array}$ & \\
\hline at $30 \mathrm{y}$ & & & \\
\hline at $50 \mathrm{y}$ & & & \\
\hline at $60 \mathrm{y}$ & & & years \\
\hline at $70 \mathrm{y}$ & & at the age of & \\
\hline $\begin{array}{l}\text { the highest } \\
\text { measured body } \\
\text { weight }\end{array}$ & & & \\
\hline Physician's measurement & & & \\
\hline
\end{tabular}

Thanks for your cooperation.

date,

your family physician 